\title{
AN EMPIRICAL STUDY ON THE IMPACTS OF INSPIRATIONAL LEADERSHIP ON FACULTIES FROM BUSINESS SCHOOL WITH SPECIAL REFERENCE TO JAIPUR
}

\author{
Dr. Teena Pareek \\ Assistant Professor, JECRC University, Jaipur, Rajasthan, India \\ Dr. Kirti Choudhary \\ Assistant Professor, JECRC University, Jaipur, Rajasthan, India \\ Udita Agrawal \\ Assistant Professor, JECRC University, Jaipur, Rajasthan, India
}

\begin{abstract}
The global pressures, competitive work environment and advancement in information technologies are posing numerous challenges before organizations in order to grow and to sustain for longer period of time. In this scenario Human resources system is facing a tough time at work and is forced to perform very well or perish completely. All the committed and dedicated employees of organization who work tirelessly in realizing their aspirations and are striving hard in attaining their organizational goals are termed as engaged employees. Employees need to be inspired and guided by senior leaders so that they can perform more effectively being result oriented. The task of transformational leaders here is to instill among their employees a sense of commitment and dedication. The present paper is aimed at exploring the role and impact of transformational leadership on employee engagement, keeping these points in mind, and will also discuss the proper relationship between the two.
\end{abstract}

Key words: Employee engagement; Transformational leadership; Academic staff; Nonacademic staff; business education

Cite this Article: Teena Pareek, Kirti Choudhary and Udita Agrawal, An Empirical Study on the Impacts of Inspirational Leadership on Faculties from Business School with Special Reference to Jaipur, International Journal of Management, 11(12), 2020, pp 2890-2900.

http://iaeme.com/Home/issue/IJM?Volume=11\&Issue=12 
An Empirical Study on the Impacts of Inspirational Leadership on Faculties from Business School with Special Reference to Jaipur

\section{INTRODUCTION}

In this competitive business culture the organizations are expected to continuously innovative, shine and exceed their competitors. The success ratio of organizations lies in the development and managing capable and competent human resources who can bestow significantly towards organizational growth and development. Organizations need to possess efficient, effective and dedicated employees who can engage and dedicate themselves in attaining organizational goals and objectives. Such employees are attributed as 'engaged employees' in organization. Engaged employees are highly motivated and committed towards increasing productivity of organizations. They are highly enthusiastic and passionate about work and strive hard to perform hard in accomplishing their tasks.

According to Kular et al. (2008) to achieve organizational outcomes engaging employees play a critical role. It demands for the role of inspirational leaders who can inspire and motivate their teammates to work together in attaining organizational objectives. Inspirational leaders inculcate a sense of positivity, commitment and motivation among their workers with a purpose to make them more effective and result oriented. Shamir and Howell (1999) believed that leadership is one of the difficult factors in encouraging employee engagement. It becomes way more critical for business educational institutions to retain competent and efficiently innovative employees in the face of challenging academic environment prevailing globally. Higher educational institutions significance on society is more talked about as compared to institutions of other areas as their impact on society in general and nation in particular is of way more importance as they are directly or indirectly influence societal aspirations and expectations. Keeping certain such things in view, the present paper will make an attempt to examine the effectiveness of transformational leadership on employee engagement in higher educational context.

Leaders are called visionary, altruistic and have influencing personality, who can help in building organization in developing high performance of employees and thereby lead to develop learning culture in organizations and improves job satisfaction playing very vital role in improving an organizations and its employees performance. Today's organizations are facing continues changing environment and, therefore, organizations requires to transform themselves as per the changing environment.

\section{HISTORICAL BACKGROUND OF EMPLOYEE ENGAGEMENT}

Over the past years, the way in which human resource is developed at work has been recognized as one of the primary determinant in achieving the improvement in organizational growth and performance. This is also reflected by popular idioms such as "people are our most important assets".

Back in the good old days of business world, things were easy. Companies placed individuals straight out of college on career paths; they offered workers a work for life and waved them farewell at retirement with a gold watch. The prospect of a safe working life as a business employee kept the happiness and efficiency of their workers up. Then stuff showed up. Global competition has risen, margins have begun to shrink and shareholders have become more demanding. Suddenly, the workers found that the very job protection they had relied on was vanishing at speed. Engagement is not exactly a new concept in itself; owners and managers have talked for years of engagement, in one way or another; they just used different terms to describe it. This upheaval meant that firms had to find new ways to inspire their employees to make them more successful and profitable, while employees were hoping for something else from their employers without stability. Therefore, engagement has come into being. In previous years, participation concentrated more on performance, competitiveness and the 
accomplishment of outcomes by the threat of retribution or incentive. Nevertheless, sound intellectual sense - and good teamwork - finally won out and, today, businesses invest more money on these aspects of employee interaction. This clearly implies that,' creating a motivated and loyal workforce'.

Enlightened executives have now understood that when their workers are fully aware of what is happening around them and feels that they are part of their team and organization too, every employee and organization as a whole will benefit. The tricky thing is to describe what makes a driven and enthusiastic worker and to consider how this positive attitude can translate into the results for its company's success.

It is understood from the basic literature analysis that good organizations share a fundamental ideology of giving meaning and investing in their workers. In reality, several studies have described the management of human capital as a way for companies to gain competitive advantage. In line with this, it is also an equally crucial challenge for the group to maintain its vital.

The word "commitment" comes from the research of Kahn (1990), who differentiated between being interested and disengaged at work. Beer, Specter, Lawrence, Quinn-Mills and Walton (1984), bringing humanistic influences together, developed the 'Harvard Business School' HRM concept, which centered on being the primary provider for individuals in an organization.

Paula Ketter has rightly noted that participation is all about building a society where people should not feel misused, overused, underused or exploited in light of the critical focus put on human resources.

Employee participation draws from the ideals of the 'Hierarchy of Needs' as conceptualized by Maslow at a very fundamental level, the highest stage of which is self-actualization; the culmination of the fulfillment of ability and potential of a person. This concept of 'higher order criteria' was widely overlooked in the days of scientific 'assembly line' development. Employee engagement is a common concept that has captured the eye of workplace consultants, human resources managers, and executives. Employers and employees cannot, however, readily explain workforce attendance. The definition of Wikipedia is: employee involvement is a term that is generally used as discretionary control of effort, which is when employees have choices; they will behave in a way that benefits their organizations. A dedicated employee is a person who is actively involved in and excited about his or her work.

\section{REVIEW OF LITERATURE}

\subsection{Employee Engagement}

The word involvement refers to the interest and enjoyment of a person, as well as passion for work (Harter, Schmidt, and Hayes, 2002). Kahn (1990) viewed employee engagement as harnessing the selves of company participants to their job roles; in engagement, individuals during role performances hire and articulate themselves mentally, cognitively and emotionally. Employee involvement has three elements, namely 1) vigor, 2) commitment and 3) absorption, according to Schaufeli et al. (2002). Vigor refers to the employee's relaxing and energizing contact of his or her work. Loyalty refers to the dedication, commitment and loyalty of workers to their jobs. Absorption is defined by the degree to which a worker is engrossed and committed to his work. This encourages workers to shy away from some sort of office distraction. Workplace absorption applies to an intensely committed person who finds it impossible to rest and concentrating minutely on his task (Gonzalez-Roma et al., 2006; Langelaan et al., 2006; Liorens et al., 2007). 
An Empirical Study on the Impacts of Inspirational Leadership on Faculties from Business School with Special Reference to Jaipur

The vigor of employee motivation fuels strong workers capacity, emotional endurance, intensity and resistance (Salanova et al., 2005). Dedication of employee commitment, which is marked by a sense of confidence, passion and high participation of workers in carrying out their duties (Schaufeli and Bakker, 2003 and 2006; Brown, 1996).Past research literature suggests that Utrecht Work Engagement Scale (UWES) developed by Schaufeli et al (2003) consisting of three factors namely i) vigor ii) dedication and iii) absorption is used quite extensively to measure employee engagement as compared to combined one factor model of UWES (Sharma and Rajput, 2017; Littman et al., 2013; Hallberg et al., 2006; Schaufeli et al., 2006; Balducci et al., 2010).

\subsection{Transformational Leadership}

Over the decade, numerous researches have been conducted on transformational leadership in different organizational settings. James MacGregor Burns first proposed this notion of transformational leadership in 1978. Transformational leadership, he said, is an active phase in which leaders and their adherents lift each other to greater standards of morality and inspiration. Many scholars have added and contributed to the current information bodies on transformative management. Bass (1985) expanded Burns' work by clarifying how to assess transformative leadership and how it influences the morale and success of followers. The type of transformational leadership is calculated using 5 variables: I idealized trait ii) idealized actions iii) motivating inspiration iv) intellectual stimulus v) human attention (Bass and Avolio, 2000). The field of transformational leadership has gained considerable prominence among scholars, analysts and decision makers over time. Marquis and Huston (2008) observed that transformational leaders help create a positive working climate that recognizes the interests of people and organizations. Groenewald and Ashfield (2008) find that transformational leadership minimizes the effects of uncertainty and change and effectively directs staff to achieve their occupational goals. Transformational leaders can enable employees to achieve significant results in the workplace, including improved productivity, improved quality and social problem solving (Spector, 2004). Transformational leadership requires optimistic and charismatic leadership components that resonate with employees that need to feel motivated and driven in unpredictable and volatile times (Hughes, 2010).Gibson et al. (2012) demonstrate that, by re-inventing the organization's entire ideology, structure and society, transformational leaders have the potential to encourage and empower adherents to produce outcomes better than initially expected. "Mokgolo et al. (2012) thought that "transformational leadership is essential to the accomplishment of corporate goals.

Such leaders consist of five sub-variables, which are idealized attributes: it is characterized as the degree to which a leader can instill pride in his followers. ii) Idealized action relies on the willingness of leaders to communicate their ideals and convictions to their followers. iii) Inspirational motivation refers to the process of inspiring and motivating followers to produce better results iv) intellectual stimulation refers to the ability of leaders to enable followers to be creative in generating ideas, viewpoints, opinions in realizing institutional goals v) individual consideration refers to how a leader is able to address the problems and concerns of their followers and how their needs and aspirations are fulfilled by them (Avolio and Bass 2004; Avolio and Bass 2002; Jung and Avolio, 2000; Bass \& Avolio, 1994).

\subsection{Relationship between Transformational Leadership and Employee Engagement}

Employee engagement has been found very important in enhancing organizational performance. Organizations strive hard to ensure that they possess efficient and dedicated workforce at their disposal who eventually would lead in contributing towards achieving 
organizational success effortlessly. Organizational leaders have a significant role to perform in creating an atmosphere at workplaces where each employee focuses on improving their performance. It has been noticed that research studies have made an attempt to call attention to the significance of employee engagement for organizations. However, the academic literature on the subject of employee engagement with reference to transformational leadership has found very less attention. In their research, Hayati, et al. (2014) found that transformative leadership has a significant and meaningful impact on employee engagement. Transformational leadership has a sound relationship with employee involvement, Joubert and Roodt (2011) pointed out. Bezuidenhout and Schultz (2013) argued that transformative leadership helps to match individual goals with the approach of organizations strategic goals. Transformational leadership is engaging with followers, creating a common understanding and raising the level of motivation for both the leader and his follower (Zhu et al., 2009; Gill, 2006; Walumbwa and Lawler, 2003; Harter, et al., 2002; Yukl, 1999; Kirkpatrick and Locke, 1996; Howell and Avolio, 1993) have highlighted that, transformational leaders inspire and motivate their followers to put extra efforts and enable them to be more engaged with their work and contribute towards organizational outcomes.

The management schools must redefine their importance in their contribution to the economy and, in particular, to industrial development as a nation transcends from a cloistered economy to a free market economy, the entire world agogues with activity, in particular the economic and educational sectors.

The efficiency of every management school depends on the transformative style of management. Every year, in cooperation with leading journals, leading B-schools are researched on the basis of different criteria by different study agencies.

"The main conclusions of business school have been summarized as "an overemphasis on research at the cost of both alignment and growth of wisdom, As well as teamwork and organizational qualities or the wrong way to teach the wrong things (and maybe to the wrong people or at least at the wrong time of their careers.

\section{FACULTY JOB IN BUSINESS SCHOOL}

Often business schools struggle hard to accomplish their objectives; exploration of expertise through study and teaching. Just one of these goals will contribute to an unbalanced discipline (Treeschmann, Dennis, Northway and Nieme Jr, 2000). In education, analysis also provides the basis for deeper insight into the classroom (Motes, 1989)

It should be remembered that this crucial argument is that the professors are members of a real world culture. They may not be cocooned and segregated, but they actively push community inputs and return inputs with value applied to the community. This value addition may be either a consultant or a curriculum of management growth.

There are several ways where it is possible to improve employee participation among faculty members. This is the channels for enhancing employee participation.

The Dean/Director must be a pioneer in change, a role model in which they can be an exemplary teacher, a motivator par excellence. They should be a strong team leader, an impartial decision-maker, a "self-sacrifice" that gives their friends credit and not themselves, and be a source of motivation above all. 
An Empirical Study on the Impacts of Inspirational Leadership on Faculties from Business School with Special Reference to Jaipur

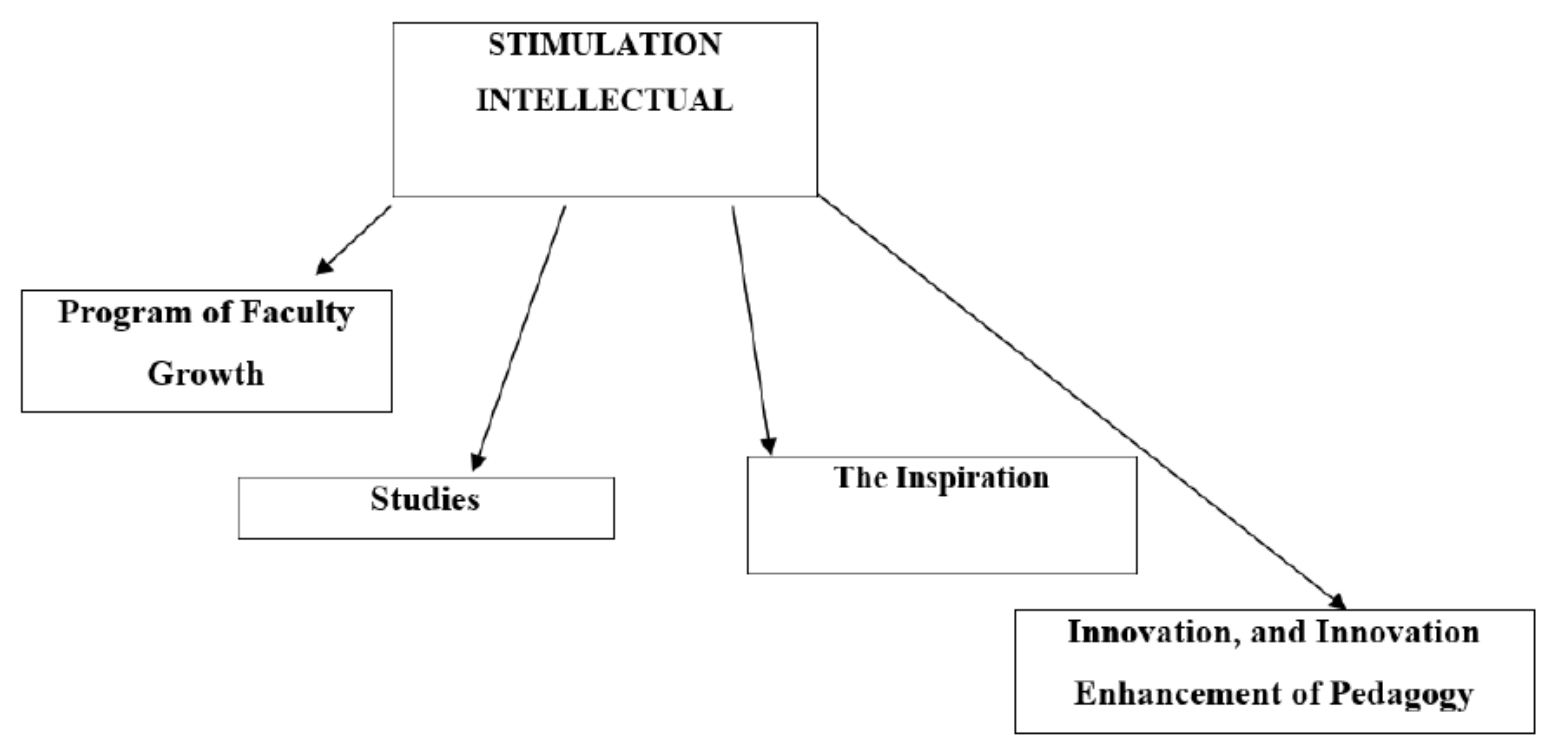

Figure 1

\subsection{Objectives of the Study}

(i)To review and analyze the perspectives of academic and non-academic workers on progressive leadership and employee engagement in a range of selected organizations.

(ii) To explore the connection between transformation leadership and employee involvement.

(iii) To find out the effects of transformational leadership on employee engagement.

(iv) To draw recommendations and suggest certain measures to improve employee interest in polling organizations in the study.

\subsection{Hypotheses of the Study}

H1 (a): Perceptions of academic and non-academic staff towards transformational leadership do not significantly differ.

H1 (b): Perceptions of academic and non-academic staff towards employee engagement do not significantly differ.

$\mathrm{H} 2$ : There exists a positive and very significant relationship between transformational leadership and employee engagement.

H3: Transformational leadership do positively and significantly effect employee engagement.

\section{RESEARCH METHODOLOGY}

A comprehensive study of primary and secondary sources was done for purpose of collecting data. A well systematic questionnaire was designed to elicit responses from different colleges of Jaipur region. There was a total of 150 questionnaires issued, of which 123 were collected. Of the 123 questionnaires that were returned, six were incomplete. For quantitative analysis, the remaining 117 accurate and full questionnaires were used. It reflected a 78.00 percent available response rate.

Analysis of the obtained data was carried out using SPSS 20.0.0. Ver. Edition. Descriptive statistics such as average score, mean score ratio, Std. Deviation, frequency has been used to research the understanding of the employee with respect to transformational leadership strategies and aspects of employee engagement. For hypothesis checking purposes, inferential statistics such as Pearson correlation is used. 
Cronbach Alpha's internal consistency coefficients are calculated to find reliability of the constructs under study and to obtain dependable picture of internal consistency of the measuring instruments. The results of the reliability test given in Table 1 reveal that the Cronbach's alpha values for all the five dimensions of transformational leadership practices and three elements of employee engagement are above the threshold level of 0.7 reflecting that the items imposed on leadership variables and employee engagement are consistently measuring its constructs.

Table 1 Reliability Analysis of Study Variables

\begin{tabular}{|l|c|c|}
\hline \multicolumn{1}{|c|}{ Construction } & No. of Products & Reliability \\
\hline Attribute to Idealized & 4 & .75 \\
\hline Behavior Idealized & 4 & .72 \\
\hline Motivation Inspiration & 4 & .79 \\
\hline Intellectual Stimulation & 4 & .80 \\
\hline Individual Consideration & 4 & .84 \\
\hline Vigor & 3 & .72 \\
\hline Absorption & 3 & .83 \\
\hline Dedication & 3 & .77 \\
\hline
\end{tabular}

\section{DATA ANALYSIS AND DISCUSSION}

Table 2 depicts the comparison between teaching and non- teaching staff's perception towards leadership practices. It has been reported from Table 2 that teaching staff (mean score $=3.43$ ) shows slightly higher satisfaction towards leadership practices as compared to non- teaching staff (mean score $=3.37$ ). Moreover, teaching personnel have also perceived higher satisfaction level towards all elements of transformational leadership as compared to non-teaching staff. The highest satisfaction level was shown towards the element inspirational motivation by both teaching (3.48) and non-teaching staff (3.42). Similarly, teaching and non-teaching staff showed least satisfaction level towards the element individual consideration (3.37) and (3.31) respectively.

However, the results of $\mathrm{z}$ test, administered to ascertain whether the difference in the mean scores reported by the teaching and non- teaching staff with respect to leadership practices, is statistically significant or merely an outcome of chance factor, indicated that the difference in the mean scores is statistically insignificant ( $\mathrm{z}$ value $=0.077 ; \mathrm{p}>.05$ ), indicating that there is no significant difference in the perception levels of male and female teaching staff with respect to leadership practices (Table 2). Hence, hypothesis (1a) is accepted indicating that the perception of teaching and nonteaching staff towards leadership practices is more or less same.

Table 2: Comparison of Employee Perception towards Transformational Leadership

\begin{tabular}{|l|c|c|c|c|}
\hline \multicolumn{1}{|c|}{ Construct } & $\begin{array}{c}\text { Mean score } \\
\text { Teaching Staff(N=76) }\end{array}$ & $\begin{array}{c}\text { Mean score } \\
\text { Non- Teaching Staff (N=41) }\end{array}$ & $\begin{array}{c}\text { Total } \\
\text { Mean } \\
\text { Score }\end{array}$ & Z Value* \\
\hline Idealized Attribute & 3.42 & 3.36 & 3.39 & .047 \\
\hline Idealized Behaviour & 3.46 & 3.38 & 3.42 & .040 \\
\hline Inspirational Motivation & 3.48 & 3.42 & 3.45 & 072 \\
\hline Intellectual Stimulation & 3.42 & 3.38 & 3.40 & .089 \\
\hline Individual Consideration & 3.37 & 3.31 & 3.34 & .054 \\
\hline Individual Consideration & 3.43 & 3.37 & 3.40 & .077 \\
\hline
\end{tabular}

${ }^{*} p<.05$;

Note: Higher the \% of mean score, higher is the level of satisfaction. 
An Empirical Study on the Impacts of Inspirational Leadership on Faculties from Business School with Special Reference to Jaipur

Table 3 depicts the comparison between teaching and non-teaching staff's perception towards employee engagement. It has been reported from Table 3 that teaching staff (mean score $=3.34$ ) shows slightly higher satisfaction towards employee engagement as compared to non- teaching staff (mean score $=3.28$ ). However, teaching staff have shown highest satisfaction towards the element dedication (3.38) while as nonteaching staff have shown towards vigor (3.25).

Table 3: Comparison of Employee Perception Towards Employee Engagement

\begin{tabular}{|c|c|c|c|c|}
\hline Construct & $\begin{array}{l}\text { Mean score } \\
\begin{array}{c}\text { Academic Staff } \\
(N=66)\end{array}\end{array}$ & $\begin{array}{l}\text { Mean score } \\
\text { Non- Academic } \\
\text { Staff }(N=42)\end{array}$ & $\begin{array}{l}\text { Total } \\
\text { Mean } \\
\text { Score }\end{array}$ & $\begin{array}{c}\mathrm{Z} \\
\text { Value* }\end{array}$ \\
\hline Vigor & 3.31 & 3.25 & 3.28 & .054 \\
\hline Dedication & 3.38 & 3.30 & 3.34 & .069 \\
\hline Absorption & 3.33 & 3.29 & 3.31 & .042 \\
\hline Total Score & 3.34 & 3.28 & 3.31 & .059 \\
\hline
\end{tabular}

${ }^{*} p<.05$; Note: Higher the \% of mean score, higher is the level of satisfaction.

However, the results of $\mathrm{z}$ test, administered to ascertain whether the difference in the mean scores reported by the teaching and non- teaching staff with respect to employee engagement, is statistically significant or merely an outcome of chance factor, indicated that the difference in the mean scores is statistically insignificant ( $\mathrm{z}$ value $=0.059 ; \mathrm{p}>.05$ ), indicating that there is no significant difference in the perception levels of teaching and non- teaching staff with respect to employee engagement (Table 4). Hence, hypothesis (1b) is accepted indicating that the perception of teaching and nonteaching staff towards employee engagement is more or less same.

Table 4: Relationship between Transformational Leadership and Employee Engagement

\begin{tabular}{|l|l|c|c|}
\multicolumn{5}{|c}{ (Correlation) } \\
\hline \multirow{2}{*}{$\begin{array}{l}\text { Transformational } \\
\text { Leadership }\end{array}$} & $\begin{array}{c}\text { Transformational } \\
\text { leadership }\end{array}$ & $\begin{array}{c}\text { Employee } \\
\text { Engagement }\end{array}$ \\
\cline { 2 - 4 } & Pearson Correlation & 1 & $.508^{\wedge \wedge}$ \\
\cline { 2 - 4 } & Sig. (2-tailed) & & .000 \\
\cline { 2 - 4 } & $\mathrm{N}$ & $.508^{\wedge \wedge}$ & 151 \\
\hline \multirow{2}{*}{ Employee Engagement } & Pearson Correlation & .000 & 1 \\
\cline { 2 - 4 } & Sig. (2-tailed) & 117 & 117 \\
\cline { 2 - 4 } & $\mathrm{N}$ & 117 & 117 \\
\hline
\end{tabular}

**. Correlation is significant at the 0.01 level (2-tailed).

It can be shown from Table 4 that there is a strong and essential association between transformational leadership and employee involvement in selected sample organizations. It depicts that the more we exhibit transformational leadership in select institutions, the more it will result in promoting employee engagement of academic staff. Therefore, our hypotheses 2 is supported since correlation between transformational leadership practices and employee engagement was found $(\mathrm{r}=.508, \mathrm{p}=0.000)$ which is both positive as well as statistically significant.

Further, in order to examine the effect of transformational leadership on employee engagement, regression analysis was performed (Table 5). The regression analysis indicates that the perception of teaching and non-teaching staff regarding transformational leadership practices has a significant positive effect on employee engagement prevailing in sample select institutions. The value of $\mathrm{R} 2=0.426$, shows that $42.06 \%$ variance is explained by independent variable (transformational leadership) in dependent variable (employee engagement). Thus our 
hypothesis 3 is accepted. Hypotheses 3 states that transformational leadership influence employee engagement.

Table 5 Effect of Transformational Leadership Practices on OCTAPACE Culture

\section{(Regression Analysis)}

\begin{tabular}{|c|c|c|c|c|c|}
\hline \multicolumn{7}{|c|}{ Model Summary } & \\
\hline Model & R & R Square & Adjusted R Square & F-Value & Sig. \\
\hline 1 & $.508 \mathrm{a}$ & .426 & .425 & 96.09 & $.000 \mathrm{a}$ \\
\hline
\end{tabular}

\section{CONCLUSION}

This research examined the existing perception of academic and non-academic staff towards transformational leadership and employee engagement in sample study institutions. It was found that transformational leadership and employee engagement is perceived positively by academic and non-academic staff of sample select institutions.

This research also revealed that there exists a favorable and important relationship between transformational leadership and employee engagement. Further, on the basis of findings it is concluded that transformational leadership positively and significantly affect and influence employee engagement. The review of this report also found out that, as opposed to nonacademic employees, academic staff displayed a higher degree of satisfaction with both transformational leadership and employee involvement. The findings of the analysis found that, relative to other transformational leadership components, idealized behavior and inspirational motivation showed greater satisfaction levels. As leaders have to display these styles more often due to its acceptability among academic staff. Elements such as individual consideration, intellectual stimulation and idealized qualities need to be more centered by management so that workers believe that their interests are more understood, empowered and encouraged to work successfully, and offered an atmosphere where their insights and opinions can be supported in a constructive way. Moreover, among the elements of employee engagement, the element of dedication was perceived in a more favorable manner by academic staff while as element vigor showed least satisfaction among the subscales of employee engagement.

This research faced with some limitations. Firstly, the study targeted only four colleges in Jaipur region and that too with less sample size. As such the findings of the research cannot be generalized to whole population. Therefore, future research can include universities as well, so as to present broader perception towards study variables. Secondly, no demographic variable was examined in the present study therefore future research can consider factors namely age, gender, and designation so that transformational leadership practices and employee engagement elements can be studied more holistically.

\section{REFERENCES}

[1] Avolio, B. J., \& Bass, B. M. (2002). Developing potential across a full range of leadership. Mahwah, NJ: Lawrence Erlbaum Associates.

[2] Avolio, B. J., \& Bass, B. M. (2004). Multi-factor leadership questionnaire manual and sampler set (3rd ed.). Palo Alto, CA: Mind Garden.

[3] Balducci, C., Fraccaroli, F., \& Schaufeli, W. B. (2010). Psychometric properties of the Italian version of the Utrecht work engagement scale (UWES-9). European Journal of Psychological Assessment, 26(2), 143-149.

[4] Bass, B. M. (1985). Leadership and performance beyond expectations. New York: Free Press. 
An Empirical Study on the Impacts of Inspirational Leadership on Faculties from Business School with Special Reference to Jaipur

[5] Bass, B. M., \& Avoilio, B. J. (1994). Improving organizational effectiveness through transformational leadership. Thousand Oaks, CA: Sage Publications.

[6] Bezuidenhout, A. \& Schultz, C. (2013). Transformational leadership and employee engagement in the mining industry. Journal of contemporary management, 10(1), 279- 297.

[7] Brown, S. P. (1996). A meta-analysis and review of organizational research on job involvement. Psychological Bulletin, 120, 235-255.

[8] Burns, J.M. (1978). Leadership. New York, NY: Harper \& Row.

[9] Gibson, J.L, Ivancevich, J.M, Donnely, J.H \& Konopaske, R. (2012). Organizations: behaviour, structure, processes. Boston: McGraw-Hill.

[10] Gill, R. (2006). Theory and practice of leadership. Thousand Oaks: Sage Publications Ltd.

[11] Gonzalez-Roma V. Schaufli, W.B. Bakker A. B. \&Lioret, S. (2006). Burnout and work engagement. Journal of Vocational Behaviour, 68, 165-174.

[12] Hallberg, U. E., \& Schaufeli, W. B. (2006). "Same same" but different? Can work engagement be discriminated from job involvement and organizational commitment? European psychologist, 11(2), 119-127.

[13] Harter, J. K., Schmidt, F. L., \& Hayes, T. L. (2002). Business-unit-level relationship between employee satisfaction, employee engagement, and business outcomes: A metaanalysis. Journal of Applied Psychology, 87(2), 268-279.

[14] Hayati, D. Charkhabi, M., \& Naami, A.Z. (2014). The relationship between transformational leadership and work engagement in governmental hospitals nurses: a survey study. Springer Plus, 3(25), 3-25.

[15] Howell, J. M., \& Avolio, B. J. (1993). Transformational leadership, transactional leadership, locus of control, and support for innovation: Key predictors of consolidated business-unit performance. Journal of Applied Psychology, 78(6), 891-902

[16] Hughes, M. (2010). The leadership of change. In M. Hughes (Ed). Managing change: A critical perspective, pp. 135-149. London: CIPD.

[17] Jacobs, R. L. (2003). Structured on-the-job training: Unleashing employee expertise in the workplace. San Francisco: Berrett-Koehler.

[18] Joubert, M. \& Roodt, G. (2011). Identifying enabling management practices for employee engagement. Acta Commercii, 11(1), 88-110.

[19] Jung, D. I., \& Avolio, B. J. (2000). Opening the black box: An experimental investigation of the mediating effects of trust and value congruence on transformational and transactional leadership. Journal of Organizational Behavior, 21, 949-964.

[20] Kahn, W. A (1990). Psychological conditions of personal engagement and disengagement at work. Academy of Management Journal, 33(4), 692-724.

[21] Kirkpatrick, S. A., \& Locke, E. A. (1996). Direct and indirect effects of three core charismatic leadership components on performance and attitudes. Journal of Applied Psychology, 81(1), 3651 .

[22] Latham, G. P., \& Pinder, C. C. (2005). Work motivation theory and research at the dawn of the twenty-first century. Annual Review of Psychology, 56(1), 485-516.

[23] Liorens, S. Schaufeli, W.B, Bakker, A. \& Salanova, M. (2007). Does a positive gain spiral of resources, efficacy beliefs and engagement exist? Computers in Human Behavior, 23(1), 825841. 
[24] Littman-Ovadia, H., \& Balducci, C. (2013). Psychometric properties of the Hebrew version of the Utrecht work engagement scale (UWES-9). European Journal of Psychological Assessment, 29(1), 58-63

[25] Marquis, B.L \& Huston, C. J. (2008). Leadership roles and management functions in nursing theory and application. Sixth edition. China: Wolters Kluwer Health/Lippincott Williams and Wilkins.

[26] Mokgolo, M. M., Mokgolo, P. \& Modiba, M. (2012). Transformational leadership in the South African public service after the April 2009 national elections. South African Journal of Human Resource Management, 10(1), 1-9.

[27] Northouse, P. G. (2010). Leadership, theory and practice. 5th Edition, Thousand Oaks, California: Sage Publications.

[28] Schaufeli, W. B., Bakker, A. B., \& Salanova, M. (2006). The measurement of work engagement with a short questionnaire: A cross-national study. Educational and Psychological Measurement, 66(4), 701-716.

[29] Salanova, M., Agut, S. \& Peiro, J. M. (2005). Linking organizational resources and work engagement to employee performance and customer royalty. Journal of Applied Psychology, 90(6), 1217-1227.

[30] Shamir, B., \& Howell, J.M. (1999). Organizational and contextual influences on the emergence and effectiveness of charismatic leadership. Leadership Quarterly.

[31] Sharma, U., \& Rajput, B. (2017). Work engagement in India: Psychometric evaluation of Utrecht work engagement scale. MANTHAN: Journal of Commerce and Management.

[32] Spector, P. E (2004). Industrial and organizational psychology: Research and practice. New York, NY: John Wiley.

[33] Steers, R. M., Porter, L. W., \& Bigley, G. A. (2004). Motivation and leadership of work. New York: McGraw-Hill.

[34] Steers, R. M., Porter, L. W., \& Bigley, G. A. (2004). Motivation and leadership of work. New York: McGraw-Hill.

[35] Yukl, G. (1999). An evaluation of conceptual weaknesses in transformational and charismatic leadership theories. Leadership Quarterly. 